\section{Aplikasi Algoritma Data Mining pada Bidang Teknik Sipil}

\section{Bambang lareno}

Program Studi Teknik Informatika, STMIK Indonesia Banjarmasin

$\triangle$ blareno@stmik.id

\section{Pendahuluan}

Teknik Data Mining dan juga dalam hal ini softcomputing, semakin terkenal dalam beberapa tahun terakhir karena potensinya dalam memecahkan masalah-masalah perencanaan dalam keseharian seorang insinyur.

Teknik-teknik dalam Data Mining dan Softcomputing seperti: Classical Optimization, Evolutionary Algorithms, Big Data Analytics, Multicriterion Decision Making, jaringan Syaraf Tiruan, Machine Learning, and Logika Fuzzy merupakan hal yang disukai profesional teknik sipil dalam menganalisa sesuatu.

Davenport(Davenport, 2013) menunjukkan bahwa ada tiga jenis analitik: (1) deskriptif, laporan mana di masa lalu yang melaporkan apa yang terjadi?,
Teknik Data Mining dan juga dalam hal ini soft computing, semakin terkenal dalam beberapa tahun terakhir karena potensinya dalam memecahkan masalah-masalah perencanaan dalam keseharian seorang insinyur. Hal itu membawa kepada perlu adanya perubahan budaya dalam cara bekerja dan berpikir. Metode penelitian yang dilakukan adalah dengan melakukan studi terhadap literatur yang berkaitan dengan teknik sipil, dan kemudian mengelompokkannya ke dalam bidang-bidang kerja teknik sipil. Dari analisis dapat disimpulkan pemimpin organisasi akan memainkan peran penting. Pendorong utama dalam menggunakan data mining dalam keteknikan adalah terkait dengan keberlanjutan, peningkatan proses, peningkatan mutu, penyelidikan persaingan pasar, kepastian biaya dan pengurangan biaya, kepastian kinerja dan sistem pendukung keputusan yang efektif dan efisien.

Kata kunci: klasifikasi, prediksi, optimasi, estimasi.

Diajukan: 13 September 2019

Direvisi: 14 September 2019

Diterima: 2 Oktober 2019

Dipublikasikan online: 3 Oktober 2019 (2)prediktif, yang menggunakan model berdasarkan data masa lalu untuk memprediksi masa depan dan untuk menentukan apa yang bisa terjadi?, dan (3)preskriptif, yang menggunakan model untuk menentukan perilaku, tindakan, dan jawaban optimal apa yang harus dilakukan?.

Data Mining menganalisis sejumlah besar data untuk menemukan pola yang bermakna dengan menggunakan kombinasi aturan pengenalan pola (pattern recognition), aturan statistik, serta aturan yang diambil dari pembelajaran mesin(Ledolter, 2013). Gambar 1 menyoroti penempatan data mining pada spektrum Analisa Bisnis. Dapat dilihat bahwa data mining terutama berada di bawah analitik prediktif di mana kompleksitasnya lebih tinggi daripada analitik deskriptif.

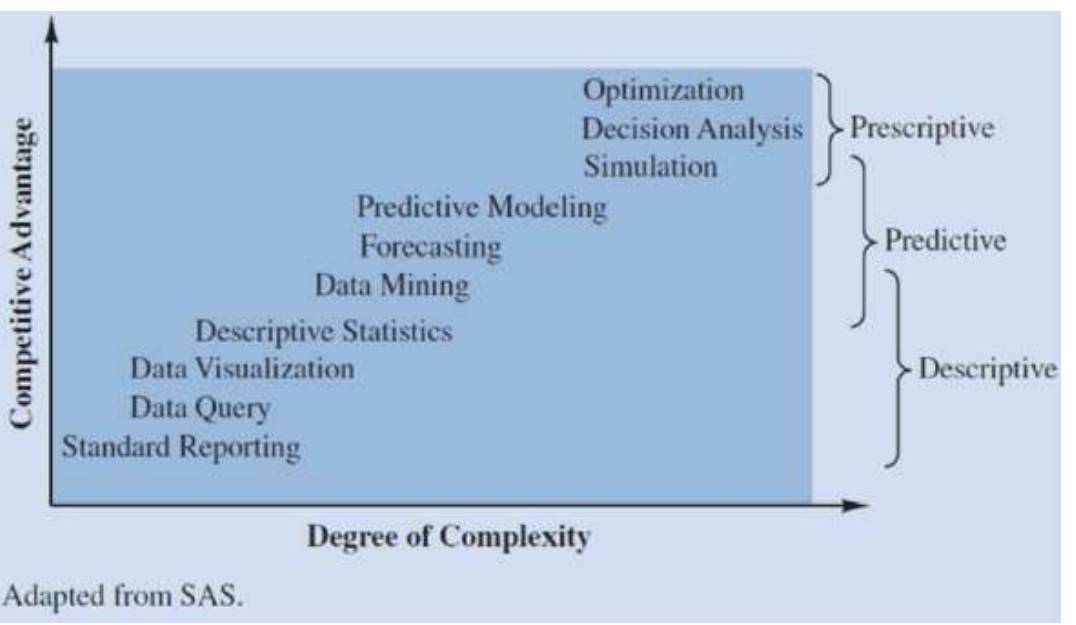

Gambar 1. Spektrum Analisa Bisnis

Cara mensitasi artikel ini:

Lareno, B (2019) Aplikasi Algoritma Data Mining pada Bidang Teknik Sipil. Buletin Profesi Insinyur 2(2) 086-090 
Pola-pola yang ditemukan harus bermakna karena mengarah pada keuntungan dalam pengambilan keputusan. Meskipun cara tradisional dalam mengambil keputusan dalam organisasi konstruksi didasarkan pada pengalaman para insiyur, kondisi pasar yang sengit dalam dunia konstruksi saat ini membutuhkan ketelitian dan peningkatan proses untuk menghindari risiko yang terkait dengan masalah keuangan dan manajemen proyek(Mehta, 2010).

Fokus paper adalah bagaimana menggambarkan aplikasi Algoritma Data Mining pada bidang Teknik Sipil. Pada bagian pertama dari papar ini, menjelaskan konsep data mining. Pada bagian kedua, aplikasi data minig yang telah diajukan dalam berbagai bidang teknik sipil.

Jadi Paper ini ditujukan untuk memberikan gambaran apa saja yang dapat disumbangkan oleh algoritma data mining untuk membantu menyelesaikan masalah yang dihadapi teknik sipil.

\section{Metode Penelitian}

Dalam paper ini, literatur yang terkait dengan istilah Data Mining (termasuk big data) telah ditinjau berdasarkan artikel-artikel yang terdapat dalam database koleksi Thomson Reuters Web of Science, dalam rentang 2000-2019.

Karena itu pada bagian ini, pertama-tama menjelaskan konsep data mining, dan kemudian secara singkat bagaimana algoritma ini diaplikasikan dalam berbagai bidang teknik sipil.

\section{Data Mining}

Data mining adalah istilah yang digunakan untuk mendeskripsikan penemuan pengetahuan dari sejumlah besar data. Beberapa teknik yang termasuk data mining antara lain knowledge extraction, pattern analysis, data archaeology, information harvesting, pattern searching, dan data dredging(Daniel T, 2005).

Bagaimana Data mining Bekerja? Data mining secara umum mencari untuk mengidentifikasikan empat tipe pattern utama yaitu:

- Asosiasi, menemukan secara umum mengacu pada pengelompokan hal-hal.

- Prediksi, memberitahukan kejadian-kejadian alami di masa yang akan datang di even yang tepat berdasar pada apa yang terjadi di masa lampau.

- Klaster, mengidentifikasikan pengelompokan halhal natural berdasar pada karakteristik yang diketahui.

- Relasi urutan, menemukan event dengan waktu yang berurutan.

Tiga lainnya adalah Outer, Regresi dan klasifikasi (Gambar 2). Sedang tahap-tahap umum dalam proses data mining dapat dilhat pada Gambar 3.

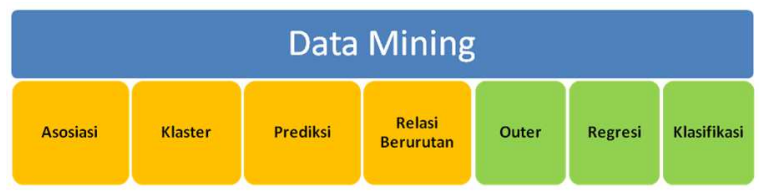

Gambar 2. Pola-pola data mining

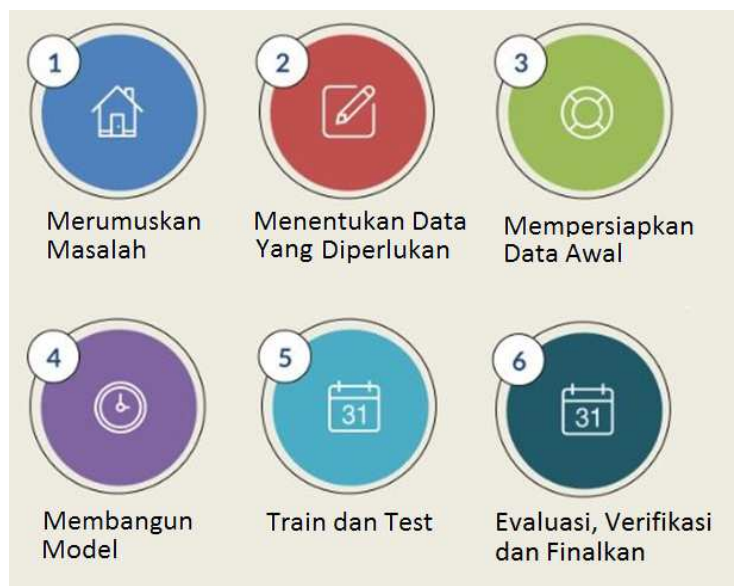

Gambar 3. Tahap dalam data mining. (courtesy@digitaltransformationpro)

Salah satu teknik dalam data mining adalah big data. Big Data adalah teknik atau cara untuk mengambil, menyimpan, memroses, dan menganalisa data-data yang sebelumnya tidak memungkinkan atau tidak ekonomis untuk diambil, disimpan, diproses, dan dianalisa. Aset informasi tersebut bervolume tinggi, berkecepatan tinggi, dan bervariatif tinggi (tidak terstruktur) yang menuntut bentuk-bentuk pemrosesan informasi inovatif yang hemat biaya untuk peningkatan wawasan dan pengambilan keputusan(Ozkose, Ari, \& Gencer, 2015).

Big Data dapat dibagi menjadi 5 kelas berdasarkan:

- Sumber Data (Web \& Social, Machine, Sensing, Transactions and loT),

- Bentuk isi (Structured, Semi-Structured and Unstructured),

- Penyimpanan Data (Document-oriented, Columnoriented, Graph based and Key-value),

- Tingkatan Data (Cleaning, Normalization and Transform) and

- Pemprosesan Data (Batch and Real time).

Berdasarkan publikasi yang ditemukan pada database Web of Science. Sebagaiman terlihat pada Tabel 1, ada 2664 publikasi, yang mencakup semua jenis dokumen, termasuk artikel, 1060. Dari jumlah itu, ada 590 publikasi yang berkait dengan teknik sipil.

Tabel 1. Publikasi data mining yang berkait dengan teknik sipil

\begin{tabular}{lc}
\hline \multicolumn{1}{c}{ Publikasi } & Jumlah \\
\hline Semua & 2.664 \\
Artikel & 1.060 \\
Terkait dengan Teknik Sipil & \\
Semua & 590 \\
Artikel & 139 \\
\hline
\end{tabular}

\section{Aplikasi Data Mining}

Dari publikasi tersebut, dipilih beberapa yang relevan dan sedapat mungkin yang terbaru. Kemudian dikelompokkan ke bidang teknik sipil, sebagai berikut: 


\section{Bidang Konstruksi}

Data Mining dapat digunakan untuk mengoptimalkan desain struktural (Leu, Chen, \& Chang, 2011), desain bangunan hemat energi dan berkelanjutan(Kim, Stumpf, \& Kim, 2011), mengklasifikasikan cacat konstruksi jembatan (Cheng \& Leu, 2011), dan memprediksi kekuatan tekan beton ramah lingkungan(Omran, Chen, \& Jin, 2016).

\section{Manajemen dan Keuangan Proyek}

Data Mining digunakan untuk Analisis kelayakan investasi(Yun \& Caldas, 2009), perkiraan biaya konstruksi jalan(Wilmot \& Cheng, 2003), optimasi kebijakan pemilihan lelang (Chaovalitwongse, Wang, Williams, \& Chaovalitwongse, 2011), analisa kinerja pembangunan(Cheng, Fu, \& Yan, 2015), analisa kecelakaan konstruksi (Ding, Fang, Luo, Love, \& Ouyang, 2018), Pemetaan harga real estat (Hromada, 2015), Manajemen Aset(Williams \& Halling, 2014), dan pemodelan simulasi operasi alat berat (lihat Gambar 4 dan 5) (Akhavian \& Behzadan, 2013).

\section{Transportasi}

Data Mining digunakan untuk memprediksi Indeks Kekasaran (IRI/International Roughness Index) perkerasan, yaitu dengan menganalisis data IRI awal, termasuk usia, Equivalent Single Axle Load (ESAL), crack, lubang, rutting, dan retakan yang panjang(Rifai, Hadiwardoyo, Correia, Pereira, \& Cortez, 2015). Selain itu, menganalisa (Sung \& Chong, 2017) dan memprediksi arus lalu lintas pada jalan raya (Lareno, 2014)

\section{Geoteknik dan Hidrologi}

Penerapan teknik datamining dalam estimasi kekuatan tekan uniaksial kolom Jet grouting dari waktu ke waktu. Jet grouting (JG) adalah teknik perawatan tanah yang merupakan solusi terbaik untuk beberapa masalah perbaikan tanah (Tinoco, Correia, \& Cortez, 2011). Selain itu, dapat digunakan untuk memprediksi besaran curah hujan (Lareno, 2015), Data besaran curah hujan, kemudian dapat diproses menggunakan HEC-HMS maun HEC-RAS, untuk penyelidikan dan memodelkan daerah aliran sungai maupun melakukan analisa hidrolika sungai terhadap bangunan air.

\section{Pembahasan}

Pada umumnya penerapan data mining dalam bidang teknik sipil dapat meningkatan kinerja dalam penggunaan waktu. Dengan efisiensi waktu, didapatkan juga efisiensi biaya, terutama pada masa perancangan atau pada evaluasi pelaksanaan konstruksi.

Banyak proyek dengan menyertakan permodelan data mining dimulai dengan tujuan yang tidak jelas dan ambigu. Sementara reaksi pertama terhadap kesimpulan semacam itu adalah bahwa seseorang harus menjadi lebih baik dalam memahami sistem dan memahami masalah secara komprehensif. Tetapi nyatanya, seringkali masalah yang harus dipecahkan diidentifikasi dan didefinisikan ulang ketika proses data mining sedang berlangsung. Dan itu memang suatu hal yang wajar dan sering ditemui.

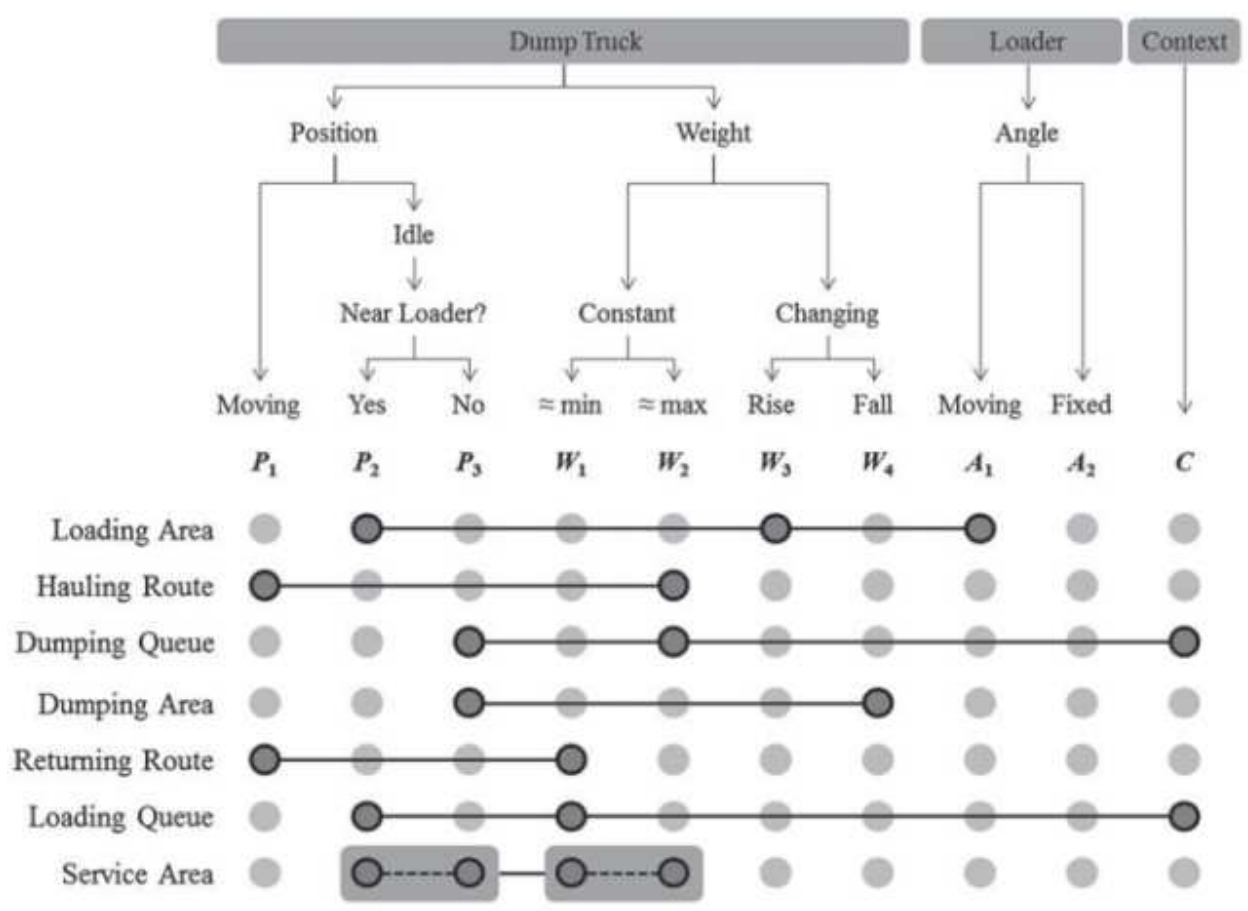

Gambar 4. Klasifikasi kegiatan dump truck dalam operasi pemindahan tanah berdasarkan proses multimodal dan konteks operasional 


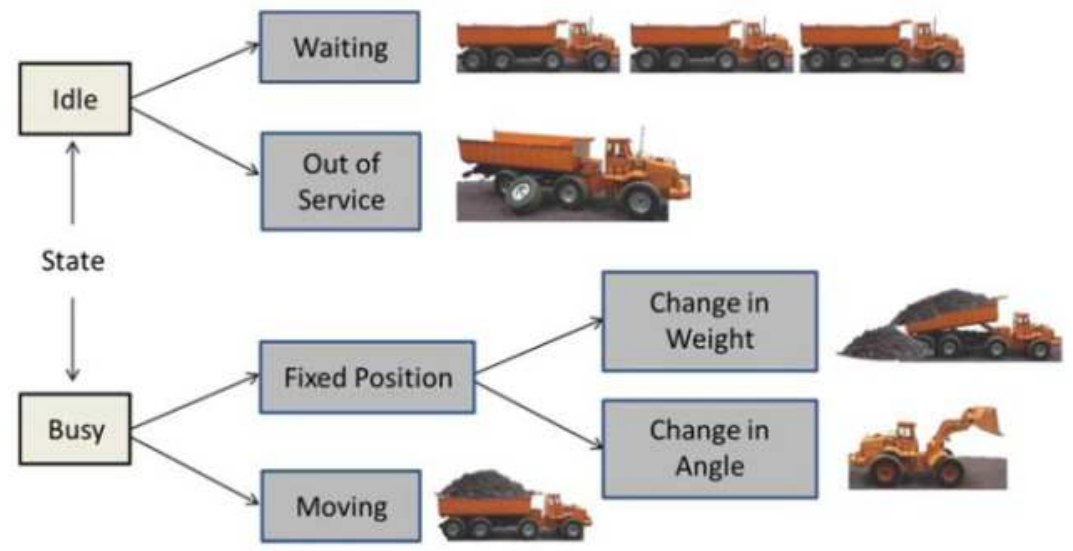

Gambar 5. Klasifikasi State berdasarkan armada alat berat

Dengan demikian, harus ada pertemuan bersama seluruh tim proyek permodelan. Terutama, lebih melibatkan ahli informatika (data miners), ahli domain (engineer), dan ahli data (surveyor). Ahli informatika membawa pemahaman statistik dan algoritmik, keterampilan pemrograman, dan kemampuan investigasi kunci yang mendasari analisis apa pun. Para ahli domain tahu tentang masalah aktual yang sedang ditangani. Para ahli data tahu tentang data, bagaimana data itu dikumpulkan, di mana data itu disimpan, bagaimana mengakses dan menggabungkan data yang diperlukan untuk analisis, dan dapat mengenali setiap keanehan dan perangkap data (false perception).

Karena itu, melakukan pendekatan dengan permodelan data mining memerlukan disiplin pencatatan dan dokumentasi proyek. Makin baik pencatatan, makin beragam data yang tercatat, akan makin baik hasil permodelan dengan data mining. Dengan demikian, untuk memastikan data-data yang diperlukan tersebut tersedia dengan baik, memerlukan kepemimpinan yang baik pula.

Penelitian penerapan data mining dalam berbagai bidang teknik sipil tersebut menunjukkan bahwa perlu ada perubahan pola pikir dan budaya dalam cara bidang ini bekerja. Pemimpin organisasi akan memainkan peran penting dalam hal ini dengan pendekatan topdown, berinvestasi dalam teknologi (data mining, khususnya big data) yang menyatukan data berharga yang dihasilkan dari berbagai lokasi dan proses yang terpecah-pecah (Kang, Yu, \& Chang, 2017), berinvestasi dalam peningkatan kesadaran dan pelatihan, dan mempekerjakan orang dengan keahlian yang diperlukan.

Dengan demikian tujuan penerapan data mining dapat memberikan keuntungan yang diharapkan.

\section{Kesimpulan}

Algoritma data mining telah digunakan dihampir setiap bidang, termasuk teknik sipil. Data mining dapat diterapkan pada segala jenis data yang diperoleh atau digunakan dalam proyek, paling tidak pada bidang yang disebutkan dalam paper ini. Keuntungan utamanya adalah rancangan desain konstruksi yang optimal dan atau penggunaan waktu proyek secara efisien, sehinggga pada akhirnya dapat mengurangi biaya proyek.

Hal itu membawa kepada perlu adanya perubahan dalam cara merancang dan mengelola proyek. Pemimpin organisasi akan memainkan peran penting. Jadi, pendorong utama dalam menggunakan data mining dalam keteknikan adalah terkait dengan keberlanjutan, peningkatan proses, peningkatan mutu, penyelidikan persaingan pasar, kepastian biaya dan pengurangan biaya, kepastian kinerja dan sistem pendukung keputusan yang efektif dan efisien.

\section{Referensi}

Akhavian, R., \& Behzadan, A. H. (2013). Knowledge-based simulation modeling of construction fleet operations using multimodal-process data mining. Journal of Construction Engineering and Management, 139 (11), 04013021: 1-11.

Chaovalitwongse, W. A., Wang, W.-b., Williams, T. P., \& Chaovalitwongse, P. (2011). Data mining framework to optimize the bid selection policy for competitively bid highway construction projects. Journal of Construction Engineering and Management, 138 (2), 277-286.

Cheng, F., Fu, X., \& Yan, a. C.-c. (2015). A framework for knowledge discovery in massive building automation data and its application in building diagnostics. Automation in Construction , 50, 81-90.

Cheng, Y.-M., \& Leu, S.-S. (2011). Integrating data mining with KJ method to classify bridge construction defects. Expert Systems with Applications , 7143-7150.

Daniel T, L. (2005). Discovering knowledge in data: An Introduction to Data Mining. Wiley Interscience.

Davenport, T. H. (2013, December). Analytics 3.0. Harvard Business Review .

Ding, L., Fang, W., Luo, H., Love, P. E., \& Ouyang, B. Z. (2018). A deep hybrid learning model to detect unsafe behavior: 
Integrating convolution neural networks and long shortterm memory. Automation in Construction , 86, 118-124.

Hromada, E. (2015). Mapping of Real Estate Prices Using Data Mining Techniques. Procedia Engineering , 123, 233-240.

Kang, Y., Yu, J., \& Chang, J. (2017). Big Data Analytics in Civil Engineering: The Case of China. SSRG International Journal of Civil Engineering .

Kim, H., Stumpf, A., \& Kim, W. (2011). Analysis of an energy efficient building design through data mining approach. Automation in Construction , 20, 37-43.

Lareno, B. (2014). Analisa dan perbandingan akurasi model prediksi arus lalu lintas. Jurnal CSRID - Universitas Potensi Utama .

Lareno, B. (2015). Penerapan Algoritma MKNN-X Untuk Prediksi Curah Hujan. Gema Aktualita - UPHS Journal , 4 (2).

Ledolter, J. (2013). Data Mining and Business Analytics with $R$. New Jersey: John Wiley\&Sons.

Leu, S. S., Chen, C. N., \& Chang, S. L. (2011). Data mining for tunnel support stability: neural network approach. Automation in Construction, 10 (4), 429-441.

Mehta, S. (2010). Business Intelligence for Construction Industry. The Master Builder , 196-198.

Omran, B. A., Chen, Q., \& Jin, a. R. (2016). Comparison of Data Mining Techniques for Predicting Compressive Strength of Environmentally Friendly Concrete. Journal Computational Civil Engineering, 30 (6).
Ozkose, H., Ari, E., \& Gencer, C. (2015). Yesterday, today and tomorrow of Big Data. Procedia - Social and Behavioral Sciences, 195: 1042-1050.

Rifai, A. I., Hadiwardoyo, S. P., Correia, A. G., Pereira, P., \& Cortez, P. (2015). The Data Mining Applied for the Prediction of Highway Roughness due to Overloaded Trucks. International Journal of Technology , 6 (5), 751761.

Sung, H. K., \& Chong, K. S. (2017). Develoment of Road Traffic Analysis Platform Using Big Data. Int'l Conf. on Advances in Big Data Analytics, (pp. 65-66).

Tinoco, J., Correia, A. G., \& Cortez, P. (2011). Application of data mining techniques in the estimation of the uniaxial compressive strength of jet grouting columns over time. Construction and Building Materials , 25 (3), 1257-1262.

Williams, T., \& Halling, M. (2014). Analyzing Asset Management Data Using Data and Text Mining. Piscataway, New Jersey: The State University of New Jersey: Department of Civil \& Environmental Engineering.

Wilmot, C. G., \& Cheng, G. (2003). Estimating future highway construction costs. Journal of Construction Engineering and Management, 129 (3), 272-279.

Yun, S.-M., \& Caldas, C. (2009). Analysing decision variables that influence preliminary feasibility studies using data mining techniques. Construction Management and Economics , 27 (1), 73-87. 